\title{
Preparation and Characterization of Biopolymer Chitosan Nanofiber from Coconut Crab Shell
}

\author{
Hamidin Rasulu ${ }^{\# \text {, Danar Praseptiangga }}$, I Made Joni ${ }^{*}$, Ari Handono Ramelan` \\ " Department of Agricultural Science, Graduate School of Sebelas Maret University (UNS), Surakarta 57126, Indonesia \\ * Department of Food Technology, Faculty of Agriculture, Khairun University, Ternate 97719, Indonesia \\ E-mail: hamidinrasulu@yahoo.com
}

*Department of Food Science and Technology, Faculty of Agriculture, Sebelas Maret University (UNS), Surakarta 57126, Indonesia

E-mail: dpraseptiangga@staff.uns.ac.id
"Department of Physics, Faculty of Mathematics and Natural Sciences, Universitas Padjadjaran, Bandung, Indonesia
"Nanotechnology and Graphene Research Center, Universitas Padjadjaran, Jatinangor 45363, Indonesia
E-mail: imadejoni@phys.unpad.ac.id
'Department of Physics, Faculty of Mathematics and Natural Sciences, Sebelas Maret University (UNS), Surakarta 57126, Indonesia
E-mail:aramelan@mipa.uns.ac.id

\begin{abstract}
The use of coconut crab shell waste as a chitosan product has the potential to be developed as a multifunctional product, especially in the form of the nanofiber. This study aims to prepare and characterization of biopolymer chitosan nanofiber from coconut crab shell. The method used in this study is an ionic gelation method using chitosan coconut crabs (chitosan CC) as the main medium, and the dispersion media is namely tripolyphosphate (TPP) with different concentrations to produce chitosan CC/TPP nanofibers. The chitosan is dissolved using glacial acetic acid $1 \%(\mathrm{v} / \mathrm{v})$ low $\mathrm{pH}$. Then the solution is dropped into a TPP solution with a concentration of $0.01,0.03,0.05,0.07 \%(w / v)$, using a magnetic stirrer at $600 \mathrm{rpm}$ for 30 minutes. The precipitate obtained is then homogenized using 30 minutes of ultrasonic at $\lambda 60 \mathrm{kHz}$. The characterization of nanofiber is made with Scanning Electron Microscopy (SEM) with a magnification of $10.0 \mathrm{kV}$. The morphological shape of the nanofiber size average value of $73 \mathrm{~nm}-610 \mathrm{~nm}$ at the concentration of chitosan CC/TPP $0.25 \%(w / v)$ and $0.03 \%(w / v)$. Particle size analysis $(P S A)$ of chitosan CC/TPP nanofibers $\left(D_{50}\right)$ at $536-625 \mathrm{~nm}$ with an average polydispersity index (PI) of 1.3 - 1.7. FT-IR analysis showed that the presence of functional groups $\mathrm{NH}, \mathrm{OH}, \mathrm{C}-\mathrm{C}, \mathrm{CH}$ varied in the concentration of $0.03 \%$ chitosan CC/TPP with the adsorption peak at wave $3257 \mathrm{~cm}^{-1} . \mathrm{X}-\mathrm{Ray}$ Diffraction shows that chitosan crystallinity obtained from various concentrations of chitosan CC/TPP shows amorphous properties because there are diffraction patterns with peaks between $18.06^{\circ}-19.04^{\circ}$. The conclusion is that the best-recommended selection is a concentration of $0.25 \%$ chitosan and $0.03 \%$ TPP to form nanofibers. The nanofiber biopolymers with the natural suspension of chitosan CC/TPP polymer produce the best pore size and can be considered as a filler in the manufacture of edible films.
\end{abstract}

Keywords - coconut crab shells; chitosan; TPP; ionic gelation; nanofibers.

\section{INTRODUCTION}

Recently research on the biopolymers from materials is greatly developed and applied for various applications such as in the food industry, medicine, and environment-friendly materials. One of the important natural material for biopolymers is chitosan. Chitosan widely applied because of its biodegradability, low toxicity, biocompatibility, and functionalities [1.2]. Chitosan usually obtains from various inexpensive sources such as crustacean wastes includes crabs, shrimp, and lobsters. Chitosan as one of polysaccharides sources of biomaterial becomes a largest utilization and distribution after cellulose [3]. Furthermore, chitosan as a new source of polysaccharides has been widely investigated such as lobster shells [4], and a combination of chitosan fishbone, shrimp shells and crab shells [5]. The functional advantages of chitosan in food and medicinal products are due to exceptional physicochemical properties function as a crosslinking coating [6]. Recently a quite detail review on chitosan for nanocomposites in the drug delivery 
system has been reported [7]. In addition, realistic regulatory study designs to assess the safety of specific products was investigated to support the specific chitosan structures tailored at nano-scaled to the needs of a diversity of industries [8].

The structures tailored of biopolymers chitosan applied in edible films or coating of food ingredients aims to act as antifungal and antibacterial [9]. Remarkably, the use of biopolymers chitosan as filler in the edible film improved physical and chemical properties such as their crystallinity and hydrophilicity of the film [10]. It was also reported that the use of chitosan as a nanocomposite film improved the film vapor barrier properties and be able to enhance the effects of nanofibers on films [11]. In addition, the existence of the bioactive substances in nano chitosan provides an opportunity to tailor a food product with multi-functions [12].

We have successfully applied a top-down the route of nanoparticles preparation by bead milling method to prepare nanoparticle suspension by using quite small beads ( 0.015 to $0.5 \mathrm{~mm}$ ) [13] and also applied for preparation of chitosan nanoparticles [14]. While other researcher used bottom-up the route on the preparation of nanoparticles by precipitation method of chitosan solution with tripolyphosphate (TPP) [15]. It is also reported the development of membrane techniques for the preparation of chitosan/TPP nanoparticles and optimizing membranes influences various parameters on the characteristics of nanoparticles, and nanoparticle stability for different storage conditions [16]. In order to obtain smaller chitosan nanoparticle size and higher index polydispersity values, the use of high concentration tripolyphosphate (TPP) surfactant $(5 \mathrm{mg} / \mathrm{mL})$ in chitosan polymer solution with controlled $\mathrm{pH}$ [17]. Many researchers have reported efforts on improved preparation of chitosan/TPP nanoparticles to diverse proposed of applications [18-19].

This paper aims to offers an alternative route to produce nanofiber chitosan and more importantly, the chitosan obtains from a coconut crab shell (CC) waste which is an endemic animal in North Maluku. The chitosan nanofibers were prepared at a various concentration of TPP and stirred at high-speed rotation. The obtained material has been characterized to know their morphology, bioactive compound, dispersity and crystallinity by advanced analysis instruments respectively. Scanning Electron Microscopy (SEM), Particle Size Analysis (PSA), Fourier-transform infrared spectroscopy (FT-IR) and X-Ray Diffraction (X$\mathrm{RD})$. The as-prepared nanofiber chitosan as a filler in biocomposite materials especially in the edible film has many potential applications for a multi-functional product.

\section{MATERIAL AND METHOD}

\section{A. Materials}

Coconut crab shells were obtained from restaurant waste in Ternate City, then processed into chitosan products the results of the deacetylation of chitin to chitosan which is characterized by deacetylation (DD 89\%) and molecular weight (Mw. $368 \mathrm{kDa}$ ). The TPP (Tripolyphosphate) dispersion media obtained from PT. Bratachem, Central Jakarta, The use of $1 \%(\mathrm{v} / \mathrm{v})$ glacial acetic acid (Merck.
Jakarta), distillate water, and chemicals to be used as analytical materials.

\section{B. Preparation of Chitosan-TPP Nanofibers}

Chitosan gel preparation was carried out by dissolving chitosan, as much as $0.25 \mathrm{~g}$, in $100 \mathrm{~mL}$ of $1 \%$ acetic acid, the prepared in 4 glass beaker of $100 \mathrm{~mL}$. Furthermore, TPP solution was made with a concentration of $0.01 \%, 0.03 \%$, $0.05 \%$, and $0.07 \%$ each in $25 \mathrm{~mL}(\mathrm{v} / \mathrm{v})$ of distillate water prepared glass beaker in a $200 \mathrm{~mL}$, then reduced size using a magnetic stirrer method with a speed of $600 \mathrm{rpm}$ for 30 minutes. Furthermore, the process of mixing chitosan CC solution into TPP solution was carried out with penetrating technique to avoid agglomeration and continued with homogenization using a magnetic stirrer for 15 minutes, then the ultrasonication method $(\lambda 60 \mathrm{kHz})$ was carried out for 30 minutes in order to prevent the occurrence clumping, then continued with homogenization method using homogenizer a $2500 \mathrm{rpm}$ for 30 minutes to separate chitosan CC/TPP solution with glacial acetic acid, to obtain chitosan nanofiber.

The sample preparation to be analyzed was carried out by drying chitosan CC/TPP nanofibers using an oven at $70{ }^{\circ} \mathrm{C}$ for 6 hours. Chitosan CC/TPP nanofiber characterization tests were carried out using Scanning Electron Microscopy (SEM), Particle Size Analysis (PSA), Fourier-transform infrared spectroscopy (FT-IR) and X-Ray Diffraction (X$\mathrm{RD})$.

\section{Characterization of Chitosan Nanofibers}

\section{1) Scanning Electron Microscopy of Chitosan Nanofibers}

Preparation chitosan CC/TPP nanofiber with a suspension consisted of $0.01 \%, 0.03 \%, 0.05 \%$, and $0.07 \%$ dried by cabinet drying 24 hours at $60{ }^{\circ} \mathrm{C}$, so that in the form of powder. Particle morphology was investigated through SEM image analysis (Shimadzu, SS 550 model). The particles are sputter-coated with a layer of gold to enable SEM visualization. The image is taken by applying an electron beam of $10-15 \mathrm{kV}$ voltage acceleration. The mean particle diameter is calculated by analysis of each image with a certain magnification using the software Meter@, version 1.1 with a differentiation threshold that is determined according to the scale of the image [20].

\section{2) Fourier Transform Infrared Spectroscopy of Chitosan Nanofibers}

Fourier Transform Infrared (FT-IR) is used to analyze organic compounds and polymeric compounds that have certain functional groups in each compound. FT-IR (Nicolet $^{\mathrm{TM}}$ iS ${ }^{\mathrm{TM}} 5$ TFS Inc) is in the fingerprint area of 400$4000 \mathrm{~cm}^{-1}$. Furthermore the nanofiber chitosan CC/TPP suspension consisted of $0.01 \%, 0.03 \%, 0.05 \%$, and $0.07 \%$ dried with 24 hour cabinet drying at $60{ }^{\circ} \mathrm{C}$. Furthermore, as much $2 \mathrm{mg}$ of nanofibers powder chitosan $\mathrm{CC}$ mixed with $100 \mathrm{mg} \mathrm{KBr}$ to be made pellets with vacuum printers, then scanning in frequency areas between $4000 \mathrm{~cm}^{-1}$ to $400 \mathrm{~cm}^{-1}$ is done. The wave numbers obtained from the measurement results are compared with the standard chitosan spectrum wavenumbers [20]. 


\section{3) Particle Size Analysis of Chitosan Nanofibers}

The size and distribution of particles was the most important characteristic in nanoparticle systems. The parameters analyzed using Particle Size Analysis (PSA) include polydispersity index (PI) and particle size distribution. Preparation of chitosan CC/TPP suspension nanofiber samples with a concentration of $0.01 \%, 0.03 \%$, $0.05 \%$, and $0.07 \%$ each taken $20 \mathrm{~mL}$ diluted using $200 \mathrm{~mL}$ distillate water then ultrasound $(\lambda 60 \mathrm{kHz})$, for 30 minutes, sample preparation follows the method [21]. Then the PSA test tube is rinsed first using a suspension sample solution. Furthermore, the sample is put into a $13 \mathrm{ml}$ volume test tube for further analysis. Particle size distribution is determined using Particle Size Analysis (BC LS 13320). With the Delsa TM Nano Series instrument that uses the Dynamic Light Scattering (DLS) technique.

\section{4) X-Ray Diffraction of Chitosan Nanofibers}

Wide-angle X-ray diffraction analysis was applied to deflect the crystallinity of prepared chitosan nanofibers with concentration chitosan CC/TPP samples concentration $0.01 \%, 0.03 \%, 0.05 \%$, and $0.07 \%$ and the patterns were recorded using a Rigaku III (Rigaku Corp; Japan) diffractometer with $\mathrm{Cu}$ radiation $(40 \mathrm{kV}, 30 \mathrm{~mA})$. Data was collected at a scanning rate of $1 \%$ minute with a scanning angle from $2^{\circ}$ to $40^{\circ}$ [22].

\section{RESULT AND DISCUSSION}

\section{A. Scanning Electron Microscopy of Chitosan Nanofibers}

Figure 1, that observations using SEM with four different TPP concentrations showed that TPP concentration $0.01 \%$ and TPP $0.03 \%$ formed homogeneous nanofibers and morphology, while the use of $0.05 \%$ TPP concentration and $0.07 \%$ TPP were irregular and film-shaped. This shows that the higher the concentration of TPP, the larger the particle size and shape of the film. While the lower the TPP concentration, the smaller the particle size and homogeneous. The particle morphology obtained depends on the ratio of the molar ratio between chitosan CC/TPP. In Figure 1b, the use of chitosan CC suspension concentration is $0.25 \%$ with TPP concentration of $0.03 \%$ in SEM results with a magnification of $10.0 \mathrm{kV}$ forming a nanofiber morphology with an average value of $73 \mathrm{~nm}-610 \mathrm{~nm}$ and tends to be uniform.

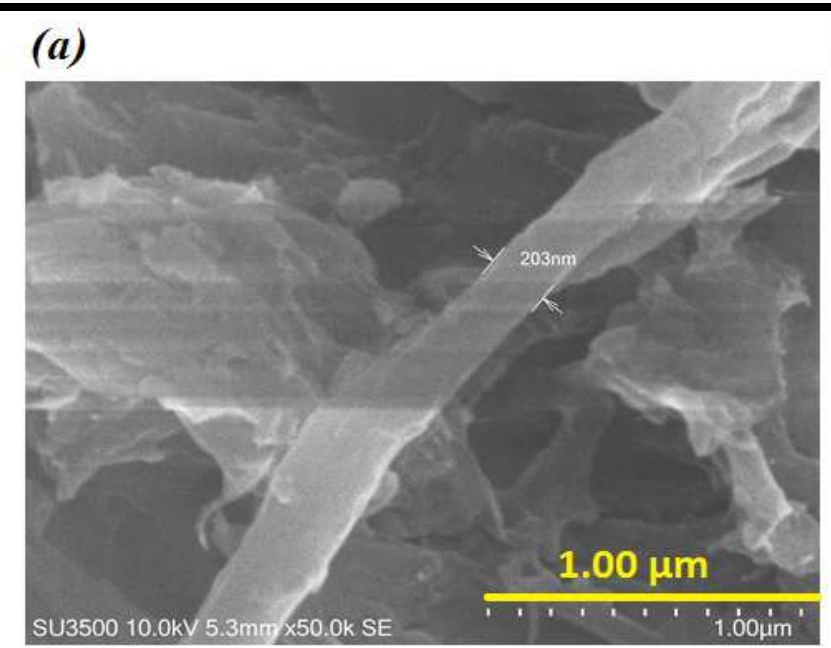

\section{(b)}

\section{(c)}

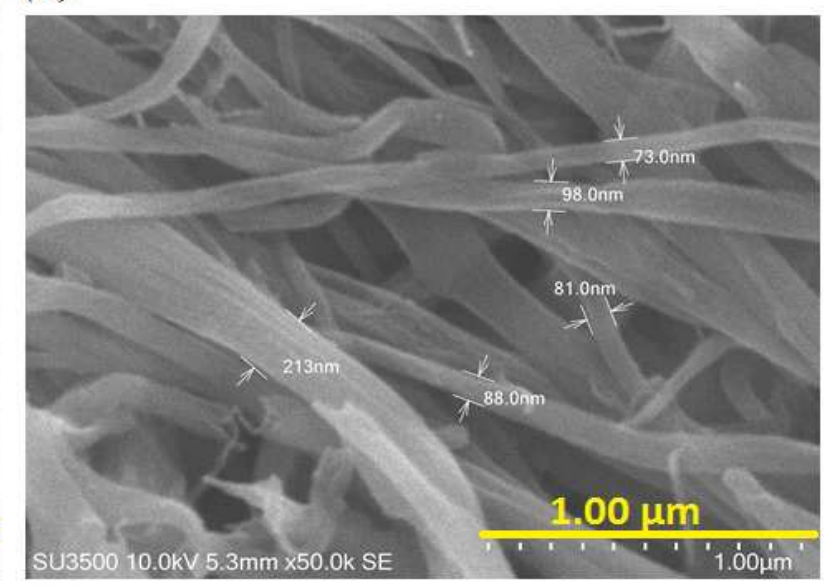

(d)
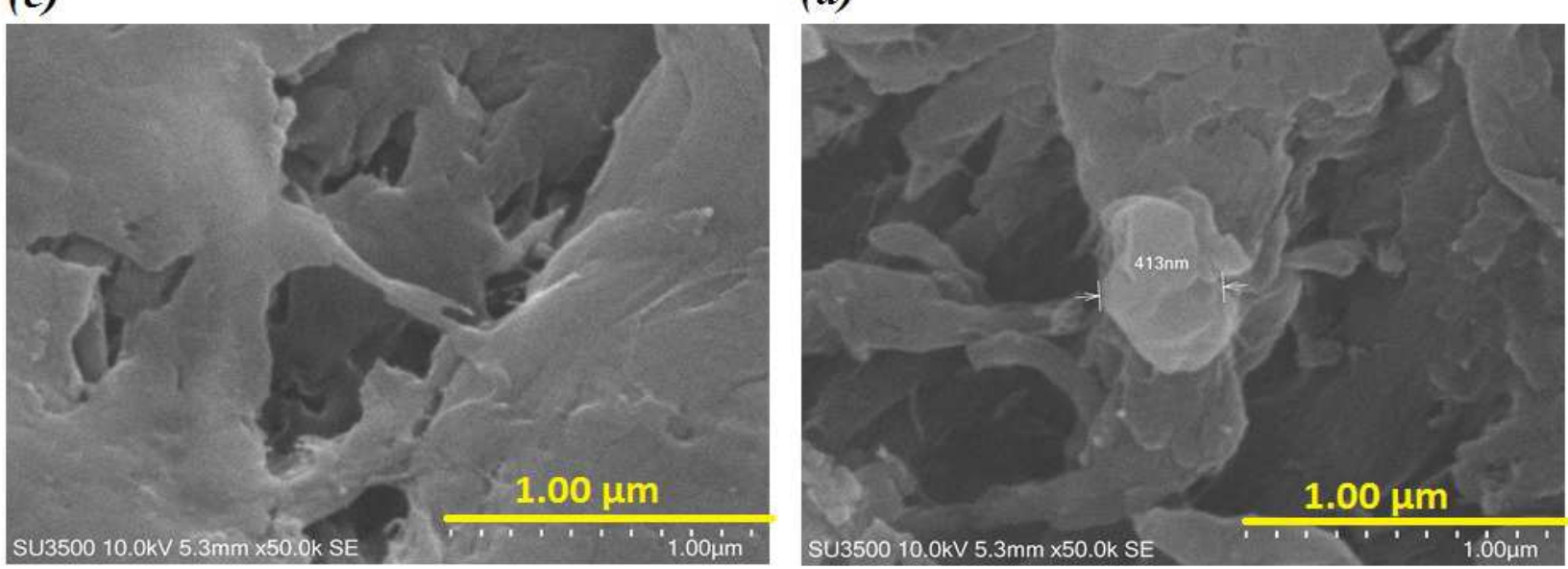

Fig 1. SEM image of the prepared Coconut Crab Chitosan (Chitosan CC) at various TPP concentration. a) 0.01 with \% TPP, b) 0.03 with \% TPP, c) 0.05 with $\%$ TPP, d) 0.07 with $\%$ TPP. 
The results of the morphological mean of chitosan CC/TPP nanofiber were strengthened by the polydispersity index (D50) of particle size analysis (PSA). The formation of a perfect morphology of nanofiber particles can be influenced by the concentration of TPP. This shows that TPP is easily soluble in water, while chitosan CC is not soluble in water and dissolves in acid, so a method of mixing chitosan CC/TPP needs to be done to obtain a nanofiber suspension. But what needs to be considered in the process of mixing between chitosan CC solution and TPP concentration is that during the mixing process with the slow penetrating technique TPP solution into chitosan CC is the occurrence of the clumping process. The characteristics of chitosan CC/TPP nanofiber have pore distances varying with the average size and polydispersity of the nanofiber equal to 115 $\mathrm{nm}$. The difference in the size of the morphology between treatments is influenced by the addition of TPP concentrations which tend to affect particle size and increase the homogeneity of its size.

Therefore the addition of TPP concentrations aims to form ionic cross bonds and as a barrier between the molecules of chitosan CC and TPP so that they can be used as absorbent materials to determine the size of the nanofiber. Conversely, increasing particle size can also be seen in Figures $1 \mathrm{a}$ and $1 \mathrm{~b}$. The longer the mixing time with the dropping method and the ultrasound, will generalize the energy received by the particles in all parts of the solution so that the size of the nanofiber is more homogeneous. In addition, the TPP concentration added will affect chitosan porosity. In Figures 1c and 1d, it is seen that the higher the concentration of TPP causes the crosslinking with chitosan to increase so that the chitosan pores CC/TPP get smaller. Chitosan CC/TPP pore sizes that are too small can cause difficulty in forming the size of nanofibers. To obtain particle size it is recommended to micro mix at optimal conditions for preparation of chitosan/TPP nanoparticles [14]. The size of the nanoparticles depends on the ratio of chitosan/TPP molar at $\mathrm{pH} \mathrm{2-5}$ and can affect the size and porosity of the particles obtained irregularly [20].

Nanoparticles were made using chitosan which had more round $\mathrm{DD}$ and 55-kDa Mv. Therefore, the size morphology was observed for particles made using chitosan 110-kDa-Mv and 55-kDa-Mv (84 $\mathrm{nm}$ and $70.6 \mathrm{~nm}$ ). Although, these results indicate that nanoparticle formation depends dramatically on the concentration of free amino groups, which increases the potential surface and zeta relationship of nanoparticles and strengthens the electrostatic interactions between nanoparticles [14]. Moreover, the resulting chitosan nanofibers (NFs) were negatively charged with SEM results showing nonporous density and morphology of nanofibrils [23]. Conversely, the transmission electron microscopic studies reveal that chitosan nanoparticles are roughly natural and have a diameter smaller than $300 \mathrm{~nm}$. Proof is shown through SEM imaging that larger particles formed nanoparticles through particle self-assembly is $25 \mathrm{~nm}$ [19].

\section{B. Fourier-Transform Infrared Spectroscopy of Chitosan Nanofibers}

Figure 2, shows the FT-IR spectra which gives a description of the spectral characteristics of particle chitosan CC, TPP, and chitosan CC/TPP from various concentrations. While, Figure 2b, the comparable FT-IR absorption value of chitosan CC which has an $85 \%$ DD value showing the same absorption peak as chitosan/TPP nanofibers, namely the spectrum of nanofibers at absorption peak at wave number $2895 \mathrm{~cm}^{-1}$ shows the presence of methyl groups and methyl groups in the chitosan structure. The formation of absorption at a size of $1650 \mathrm{~cm}^{-1}$ shows the $\mathrm{C}=\mathrm{O}$ bond which describes the presence of the acetyl group in nanofibers. The FT-IR detection results are reflected in the functional groups $\mathrm{NH}$, $\mathrm{OH}, \mathrm{C}-\mathrm{C}, \mathrm{CH}$ each in the chitosan wave number CC/TPP. Chitosan $\mathrm{CC}$ is a deacetylation result of chitin as raw material, where the degree of deacetylation of chitosan $\mathrm{CC}$ produces $2498 \mathrm{~cm}^{-1}$ absorption peak with $\mathrm{CH}$ (-CH2-) bond and chitosan absorption peak at $1620 \mathrm{~cm}^{-1}$ which contain $\mathrm{OH}$ groups, and at adsorption uptake $3510 \mathrm{~cm}^{-1}$ contained an $\mathrm{OH}$ group, while in Figure 2a it was pure TPP, indicating that the absorption peak was only at $3560 \mathrm{~cm}^{-1}$. Because it is in accordance with the stretching of the $\mathrm{NH}-\mathrm{CO}$ vibration there is an acetyl group (Figure 2f) caused by the high use of TPP concentration of $0.07 \%$. TPP absorption peak $3450 \mathrm{~cm}^{-1}$ with $\mathrm{OH}-\mathrm{NH}$ stretch vibration. Even with variations in TPP concentration using the ionic gelation method shown in Figure $2 c-2 f$, there was no significant change along with different TPP concentrations. From the observation of absorption peak $3437 \mathrm{~cm}^{-1}$ there is an -OH group, except for the $1620 \mathrm{~cm}^{-1}$ bond the absorption peak is smaller, especially in Figure 2f, showing a decrease in chitosan bond group size, while the adsorption peak is at wave $3257 \mathrm{~cm}^{-1}$.

In Figure 2c, the addition of $0.03 \%$ TPP concentration into chitosan $\mathrm{CC}$ can be seen in the spectrum having specific peaks, namely the amine group (-NH2) at wave number $1632 \mathrm{~cm}^{-1}$ and the hydroxyl group (-OH) at wave number $3420 \mathrm{~cm}^{-1}$. Absorption of the wave number of the amine group (-NH2) and hydroxyl group (-OH) in chitosan CC/TPP is at wave number $1650 \mathrm{~cm}^{-1}$ and $3450.32 \mathrm{~cm}^{-1}$. The FT-IR spectrum of Chitosan nanofiber experienced a shift in the intensity of transmittance in the spectrum region. Chitosan which has an acetyl methyl group shows that the deacetylation process is carried out optimally so that it can affect the bonds between molecules which cause differences in the absorption area. Absorption of the wavelength of $3257 \mathrm{~cm}^{-1}$ shows the presence of collective absorption, namely $-\mathrm{OH}$ and $-\mathrm{NH}$ which is found in chitosan CC/TPP suspensions with certain concentration variations. This shows that there is extensive absorption of hydrogen bonds which are intramolecular in the structure which is very strong. Although the use of $0.25 \%$ chitosan and TPP $0.01-$ $0.05 \%$ concentrations showed that chitosan was able to be dispersed with acceptable quality, there were very small amounts of the acetyl group in chitosan and the bond is more stable when compared to TPP concentration of $0.07 \%$ 


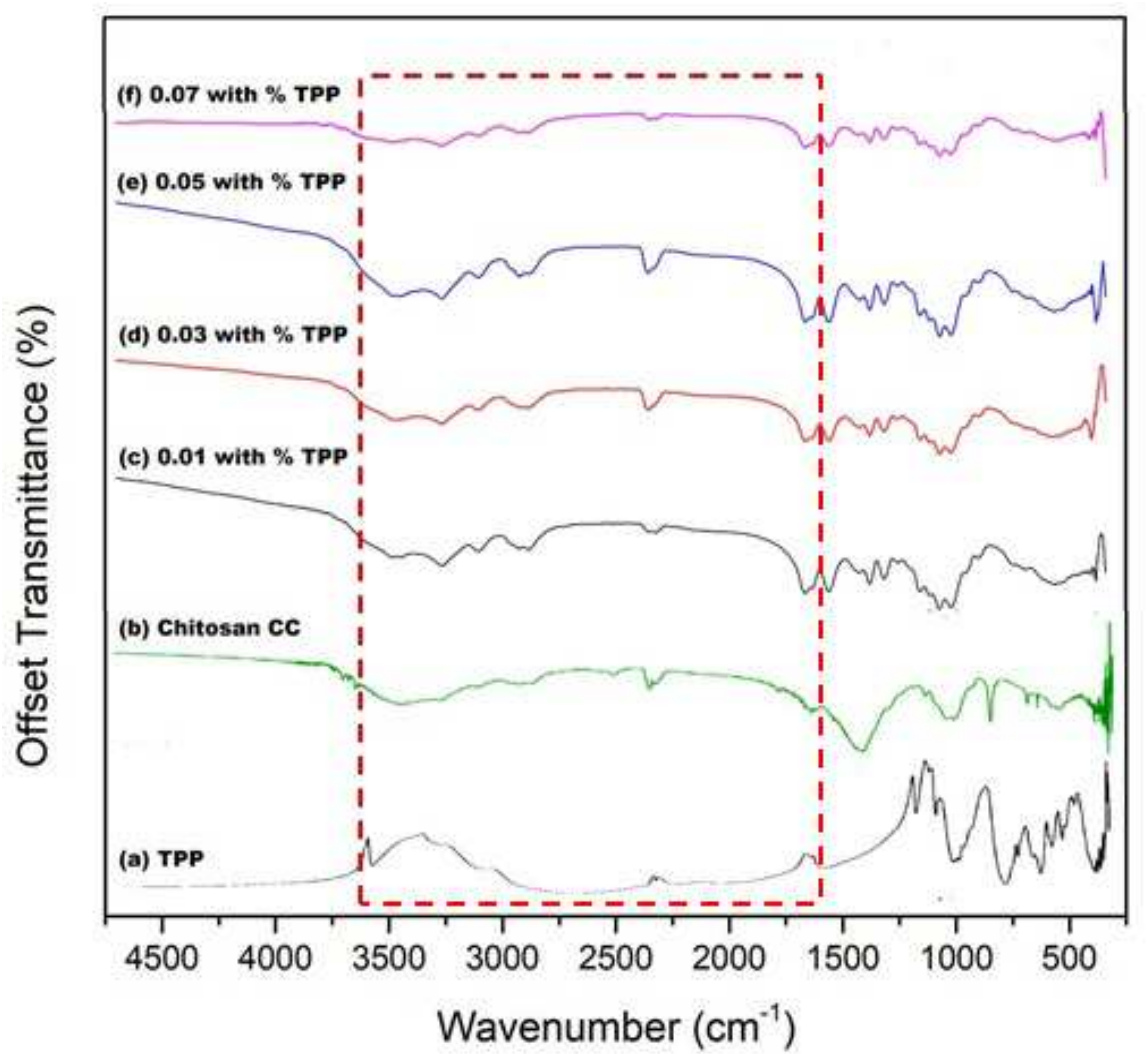

Fig 2. FT-IR Spectrum of the prepared Coconut Crab Chitosan (Chitosan CC) at various TPP concentration. a) TPP, b) Chitosan CC, c) 0.01 with \% TPP, d) 0.03 with $\%$ TPP, e) 0.05 with $\%$ TPP, f) 0.07 with $\%$ TPP.

Therefore, the deacetylation rate of crab chitosan 78.88 $81.18 \%$ can represent the number of amino groups contained in the chitosan structure [24]. Moreover, the FT-IR analysis will detect functional groups found in chitosan, namely the functional groups $\mathrm{NH}, \mathrm{OH}, \mathrm{C}-\mathrm{C}$. $\mathrm{CH}$ and $\mathrm{C}=\mathrm{O}$ for chitosan. As a result, the FT-IR detection results are reflected in the form of the peak of the functional group at each wavenumber [25]. Conversely, the FT-IR analysis on chitosan showed a degree of deacetylation of $99 \%$, in accordance with the quality standard of $\geq 70 \%$. On the other hand, the value of the degree of deacetylation gives a picture of the loss of the acetyl group $\left(\mathrm{COCH}_{3}\right)$ found in chitosan. Therefore, the high degree of deacetylation shows the purity of chitosan produced [26]. In addition to, this spectrum is similar to the chitin vibration pattern but with significant changes in position and intensity. The broad absorption band that appears in the range $3600 \mathrm{~cm}^{-1}-2800 \mathrm{~cm}^{-1}$ can be associated with collective absorption by the $\mathrm{H}-\mathrm{H}$ and $\mathrm{O}-\mathrm{H}$ groups in the polymer. Also, a good indication of extensive absorption in intermolecular structures is the presence of strong hydrogen bonds [19].

Many studies using natural materials extracted to produce nanofibers use ultrasonication techniques through nanofiber bundles by breaking down weak hydrogen strength and gradual Van der Waals bonds. The use of mechanical techniques such as ultrasonication and wet grinding methods can be used to break bonds between fibers to produce nanofibers. The use of chitosan CC solution $85 \%$ deacetylation value as an ingredient that has an amino group that can undergo protonation, and chitosan is electrostatic with anions, then TPP that can diffuse directly into chitosan are used by dropwise technique freely by using a magnetic stirrer. On the other hand, that the nature of TPP has an electrostatic attraction to $\mathrm{NH}_{3}{ }^{+}$in chitosan which results in the size of nanofibers chitosan $\mathrm{CC}$ that has a positively charged surface.

The suspension of the two ingredients namely chitosan CC/TPP is the initial result of ionic gel which has a positively charged amino group in the chitosan molecular chain, while the TPP is a negatively charged unit. The formation of nanofibers in this method is the occurrence of ionic interactions between amino groups in chitosan which are positively charged with negatively charged polyanions forming inter-and/or three-dimensional intramolecular network structures. The preparation results of chitosan nanofibers are based on ionic gelation interactions between positively charged particles namely chitosan and TPP units which are negatively charged at room temperature conditions. Then the characterization of chitosan CC/TPP nanofibers was carried out. The stability of chitosan CC/TPP aggregation decreased due to deacetylation (DD) because DD chitosan is more susceptible to connected TPP and is more lyophobic near physiologically neutral at neutral $\mathrm{pH}$ [27].

\section{Particle Size Analysis of Chitosan Nanofibers}

Figure 3A shows the nanofiber suspension of chitosan CC biopolymers and the addition of TPP with certain variations can show the success of a sample into known nanofibers visually. Then to see the size distribution and polydispersity index of the sample using PSA testing. In Figure 3B, the different particle size distribution of chitosan CC/TPP nanofibers can be seen that the particle size is almost uniform, which is smaller in size and has a lower 
polydispersity index. The addition of $0.07 \%$ TPP concentration with chitosan suspension obtained the average size of nanofibers $\left(\mathrm{D}_{10}\right)$ at $536 \mathrm{~nm}$. Conversely, with dispersion on nanofibers with a TPP concentration of low $0.01 \%$, the average size $\left(D_{10}\right)$ will be obtained at $625 \mathrm{~nm}$. However, differences in the size of chitosan CC/TPP suspension can occur because dispersing agents can form multi-layered formations. Therefore, the lower the pore distance will result in the formation of the larger and more polymerized nanofiber. However, the susceptibility of the average diameter scale to particle size has shown uniform nano size between treatments. Instead, it is suggested that the membrane does not allow the micro mix to suit process conditions, thus leading to the formation of larger and heterogeneous chitosan / TPP nanocomplexes [16].

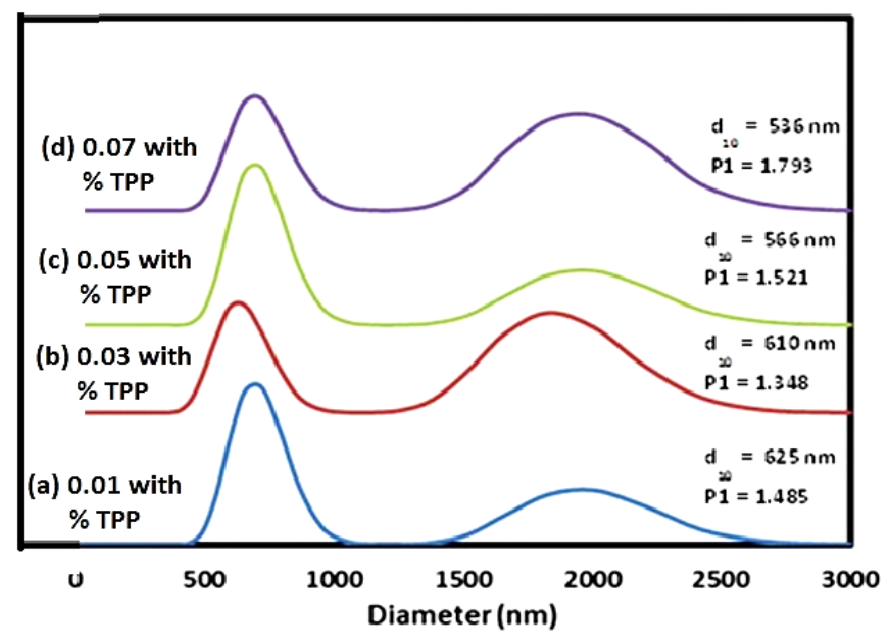

Fig 3. A). Image of Chitosan CC with TPP suspension. B). PSA of the preperied Coconut Crab Chitosan (Chitosan CC) at various TPP concentration. a) 0.01 with $\% \mathrm{TPP}$, b) 0.03 with $\% \mathrm{TPP}$, c) 0.05 with $\%$ TPP, d) 0.07 with $\% \mathrm{TPP}$.

Figure 3B shows that the most influential thing in the technology of making nanofiber is the formulation of chitosan CC/TPP by ionic gelation method. The results of the chitosan CC/TPP particle size distribution of four different treatments were influenced by the polydispersion index $(\mathrm{PI})$ value. The polydispersity index value (PI) of each chitosan CC / TPP treatment averages 1.3 - 1.7. Conversely, from the graph Figure 3B with $0.07 \%$ TPP concentration shows the particle size of chitosan CC nanofibers is smaller at $625 \mathrm{~nm}$, but the polydispersity index value is greater than that of Figure 3B using $0.03 \%$ TPP concentration with a PI value of $1348 \mathrm{~cm}^{-1}$, where the PI value determines the homogenization of a particle of nanofibers. Therefore, the smaller the polydispersity index value the more homogeneous. This is confirmed by the results of FT-IR which shows the bond in the group seen from the spectrum which has specific peaks, namely the amine group (-NH2) at the wave number $1632 \mathrm{~cm}^{-1}$ and the hydroxyl group $(-\mathrm{OH})$ at wave number $3420 \mathrm{~cm}^{-1}$. Absorption of the wave number of the amine group (-NH2) and hydroxyl group (-OH) in chitosan CC/TPP is at wave number $1650 \mathrm{~cm}^{-1}$ and 3450.32 $\mathrm{cm}^{-1}$. However, the results of all treatments show that the dispersion results are still heterogeneous where the polydispersity index value is still above 0.5 . But the polydispersity index value has a range of values from 0 to 1 , where values close to 0 indicate homogeneous dispersions, whereas values greater than 0.5 indicate high heterogeneity [28].

The use of solvent media in the form of glacial acetic acid $1 \%(\mathrm{v} / \mathrm{v})$ in chitosan CC/TPP suspension can cause an increase in surface tension in chitosan nanofibers. Although, the use of TPP dispersion media with different concentrations prevents agglomeration between particles. In addition to the probability value of adsorption dispersing agents increases on the chitosan surface [27]. Furthermore, chitosan suspension with dispersion media of various concentrations can produce nanoparticles $\left(D_{50}\right)$ at $584 \mathrm{~nm}$ with tilapia chitosan polydispersity index (PI>0.7), thus confirming the distribution of nanoparticles has a wider distribution range [24]. In addition to the chitosan CC/TPP factor, which influenced the formation of nanofibers namely the droplet and mixing process which was accompanied by stirring using a $2500 \mathrm{rpm}$ magnetic stirrer on chitosan CC/TPP suspension for each concentration. However, the results of other studies state that the stirring speed of 800 rpm with a variation of time 15 and 45 minutes will result in smaller particle size $(93 \mathrm{~nm})$ and a polydispersity index (PI> 0.24) [16].

\section{X-Ray Diffraction of Chitosan Nanofibers}

Figure 4 shows the spectrum of chitosan CC / TPP nanofiber based on XRD results from the four samples with TPP concentrations with certain variations showing amorphous properties. At $0.01 \%$ TPP concentration there is a diffraction pattern with a peak of $19.04^{\circ}$ (Figure 4a); At $0.03 \%$ TPP concentration there is a diffraction pattern with a peak of $18.06^{\circ}$ (Figure 4b); At a $0.05 \%$ TPP concentration there was a diffraction pattern with a peak of $19.00^{\circ}$ (Figure $4 \mathrm{c}$ ); and at $0.07 \%$ TPP concentration there is a diffraction pattern with a peak of $18.71^{\circ}$ (Figure $4 d$ ). The peak shift seen in the four samples has undergone a change in crystal structure into an amorphous form. The change in structure is related to the nature of biodegradability, because the more amorphous the structure, the easier it will be to break down in the body.

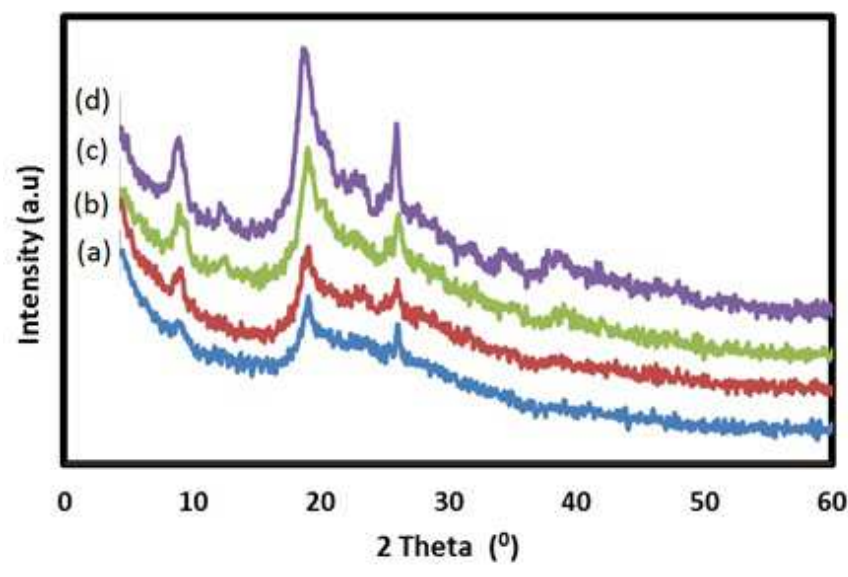

Fig 4. XRD Spectrum of the preperied Coconut Crab Chitosan (Chitosan CC) at various TPP concentration. a) 0.01 with $\% \mathrm{TPP}$, b) 0.03 with $\%$ TPP, c) 0.05 with $\% \mathrm{TPP}, \mathbf{d}) 0.07$ with $\% \mathrm{TPP}$.

The contrast in Figure $4 \mathrm{~b}$ shows that the XRD spectrum of $0.03 \%$ chitosan CC/TPP nanofibers has a more ideal amorphous structure and that there are three main diffraction 
peaks identified and located around $9.8^{\circ}, 19.5^{\circ}, 27.6^{\circ}$. Furthermore, diffraction peaks that coincide with one another show that the crystal structure has been maintained according to the ionic gelation method. During the interaction of chitosan CC/TPP in the formation of nanofibers there is a very compact bond between and intrachain molecules to be lost as shown in the FT-IR results with the addition of $0.03 \%$ TPP concentration indicating that the bonds in the group are seen from a spectrum that has specific peaks, that is, the amine group (-NH2) is a wave number $1632 \mathrm{~cm}^{-1}$ and the hydroxyl group $(-\mathrm{OH})$ is at wave number $3420 \mathrm{~cm}^{-1}$, which manifests as a decrease in crystallinity in chitosan. Therefore, the loss of crystallinity of chitosan nanoparticles allows the interaction of metal ions to occur [30].

The XRD results showed a change in shape to crystalline and SEM results showed irregular shape as a result of a cross-link between chitosan CC/TPP with a high concentration of $0.05 \%$ and $0.07 \%$, whereas a low concentration of $0.01 \%$ and $0.03 \%$ showed an amorphous form, and forming a homogeneous nanofiber. This is evidenced by the intensity reduction at the peak of $18.06^{\circ}$ as the best characteristic of chitosan CC nanofiber which forms a homogeneous nanofiber morphology as in SEM results with TPP concentration of $0.03 \%$. Therefore the incorporation of chitosan-TPP polymers showed significant especially due to the presence of phosphate residues in nanofiber. In addition, changes in the nanofiber crystallinity are influenced by the effect of chitosan properties resulting in cross-linking which results in a characteristic reduction in the form of peak intensity at $\sim 19^{\circ}$ chitosan nanofiber [31].

\section{CONCLUSIONS}

The results of the research presented in this paper also provide information about the characteristics of chitosan nanofibers as natural biopolymers using certain concentrations of chitosan CC/TPP. The results showed that the best at $0.25 \%$ chitosan and $0.03 \%$ TPP concentrations gave significant value to the formation of nanofibers, especially at smaller particle sizes and low polydispersity indexes. Thus, the functional groups of nanofibers which can be seen in the spectrum have a specific peak, that is the amine group (-NH2) is a wave number $1652 \mathrm{~cm}^{-1}$ and the hydroxyl group $(-\mathrm{OH})$ is at wave number $3420 \mathrm{~cm}^{-1}$. So the spectrum nanofibers have an ideal amorphous form. Nanofiber biopolymers with the natural suspension of chitosan CC / TPP polymer produce the best pore size and can be considered as a filler in the manufacture of edible films.

\section{ACKNOWLEDGMENT}

This research is fully supported by the scholarship funds of the Government of Indonesia through the Indonesian Institute of Education Scholarship Fund Management Institution (LPDP BUDI-DN) Indonesia. Number: PRJ4952/LPDP.3/2016.

\section{REFERENCES}

[1] M. Donmez, H.A. Oktem, and M.D. Yilmaz, "Ratiometric fluorescence detection of an anthrax biomarker with Eu3+-chelated chitosan biopolymers," Carbohydrate polymers, vol. 180, pp. 226230, 2018.

[2] K. Kim, M. Ha, B. Choi, S.H. Joo, H.S. Kang, J.H. Park, B. Gu, C. Park, J. Kim and S.K. Kwak, "Biodegradable, electro-active chitin nanofiber films for flexible piezoelectric transducers," Nano Energy, vol. 48, pp. 275-283, 2018.

[3] M. Mincea, A. Negrulescu and V. Ostafe, "Preparation, modification, and applications of chitin nanowhiskers: a review," Rev Adv Mater Sci, vol. 30(3), pp.225-242, 2012.

[4] T.T. Nguyen, A.R. Barber, P. Smith, X. Luo and W. Zhang, "Application and optimization of the highly efficient and environmentally-friendly microwave-intensified lactic acid demineralization of deproteinized Rock lobster shells (Jasus edwardsii) for chitin production," Food and Bioproducts Processing, vol. 102, pp.367-374, 2017.

[5] S. Kumari, S.H.K. Annamareddy, S. Abanti and P.K.. Rath, "Physicochemical properties and characterization of chitosan synthesized from fish scales, crab and shrimp shells," International Journal of biological macromolecules, vol. 104, pp.1697-1705, 2017.

[6] L.D.Y. Pozzo, T.F. da Conceição, A. Spinelli, N. Scharnagl and A.T. Pires, "Chitosan coatings crosslinked with genipin for corrosion protection of AZ31 magnesium alloy sheets," Carbohydrate polymers, vol. 181, pp.71-77, 2018.

[7] A. Ali and S. Ahmed, "A review on chitosan and its nanocomposites in drug delivery," International journal of biological macromolecules, 2017.

[8] G. Smets and P. Rüdelsheim, "Biotechnologically produced chitosan for nanoscale products. A legal analysis," New Biotechnology, vol. 42, pp.42-47, 2018.

[9] L.A. van den Broek, R.J. Knoop, F.H. Kappen and C.G. Boeriu, "Chitosan films and blends for packaging material," Carbohydrate Polymers, vol. 116, pp.237-242, 2015.

[10] A.I. Bourbon, A.C. Pinheiro, M.A. Cerqueira, C.M. Rocha, M.C. Avides, M.A. Quintas and A.A. Vicente, "Physico-chemical characterization of chitosan-based edible films incorporating bioactive compounds of different molecular weight. J. of Food Engineering, vol. 106(2), pp.111-118, 2011.

[11] E. Jahed, M.A. Khaledabad, H. Almasi and R. Hasanzadeh, "Physicochemical properties of Carum copticum essential oil loaded chitosan films containing organic nanoreinforcements," Carbohydrate Polymers, vol. 164, pp.325-338, 2017.

[12] G.I. Waterhouse and D. Sun-Waterhouse, "Bioactive Delivery Systems Based on Stimuli-Sensitive Biopolymer Stacks: ChitosanAlginate Systems," 2018.

[13] I.M. Joni, C. Panatarani and D.W. Maulana, "Dispersion of fine phosphor particles by newly developed beads mill," In AIP Conference Proceedings (Vol. 1712, No. 1, p. 050019), 2016.

[14] E. Rochima, S.Y. Azhary, R.I. Pratama, C. Panatarani and I.M. Joni, "Preparation and Characterization of Nano Chitosan from Crab Shell Waste by Beads-milling Method," In IOP Conference Series: Materials Science and Engineering (Vol. 193, No. 1, p. 012043), 2017.

[15] S. Kalliola, E. Repo, V. Srivastava, J.P. Heiskanen, J.A. Sirviö, H. Liimatainen and M. Sillanpää, "The $\mathrm{pH}$ sensitive properties of carboxymethyl chitosan nanoparticles cross-linked with calcium ions," Colloids and Surfaces B: Biointerfaces, vol. 153, pp.229-236, 2017.

[16] S. Hassani, A. Laouini, H. Fessi and C. Charcosset, "Preparation of chitosan-TPP nanoparticles using microengineered membranes-Effect of parameters and encapsulation of tacrine," Colloids and Surfaces A: Physicochemical and Engineering Aspects, vol. 482, pp.34-43, 2015.

[17] C.C. Sipoli, N. Santana, A.A.M. Shimojo, A. Azzoni and L.G. de la Torre, "Scalable production of highly concentrated chitosan/TPP nanoparticles in different $\mathrm{pHs}$ and evaluation of the in vitro transfection efficiency," Biochemical engineering journal, vol. 94, pp.65-73, 2015.

[18] S. Vimal, M.S. Abdul, G. Taju, K.S. Nambi, R.N. Sundar, N. Madan, M.A. Farook, T. Rajkumar, D. Gopinath and H.A. Sahul, "Retraction notice to Chitosan tripolyphosphate (CS/TPP) nanoparticles: Preparation, characterization and application for gene delivery in shrimp, " Acta tropica, vol. 168, p.91, 2017.

[19] H.C. Yang and M.H. Hon, "The effect of the molecular weight of chitosan nanoparticles and its application on drug delivery," Microchemical Journal, vol. 92(1), pp.87-91, 2009.

[20] A.F. Martins, D.M. de Oliveira, A.G. Pereira, A.F. Rubira and E.C. Muniz, "Chitosan/TPP microparticles obtained by microemulsion method applied in controlled release of heparin," International journal of biological macromolecules, vol. 51(5), pp.1127-1133, 2012. 
[21] Y. Zhang, C. Xue, Y. Xue, R. Gao and X. Zhang, "Determination of the degree of deacetylation of chitin and chitosan by X-ray powder diffraction," Carbohydrate research, 340(11), pp.1914-1917, 2005.

[22] M.T. Yen, J.H. Yang and J.L. Mau, "Physicochemical characterization of chitin and chitosan from crab shells," Carbohydrate Polymers, vol. 75(1), pp.15-21, 2009.

[23] J. You, L. Zhu, Z. Wang, L. Zong, M. Li, X. Wu and C. Li, "Liquid exfoliated chitin nanofibrils for re-dispersibility and hybridization of two-dimensional nanomaterials," Chemical Engineering Journal, vol. 344, pp.498-505, 2018.

[24] E. Rochima, S. Utami, H. Hamdani, S.Y. Azhary, D. Praseptiangga, I.M. Joni and C. Panatarani, "The dispersion of fine chitosan particles by beads-milling," In AIP Conference Proceedings (Vol. 1927, No. 1, p. 030032), 2018.

[25] D. Rachmania, "Karakteristik nano kitosan cangkang udang vannamei (Litopenaeus vannamei) dengan metode gelasi ionic, 2011.

[26] P. Suptijah, A.M. Jacoeb and D. Rachmania, "Karakterisasi nano kitosan cangkang udang vannamei (Litopenaeus vannamei) dengan metode gelasi ionic," Jurnal Pengolahan Hasil Perikanan Indonesia, 14(2), 2011.

[27] Y. Huang, Y. Cai and Y. Lapitsky, "Factors affecting the stability of chitosan/tripolyphosphate micro-and nanogels: resolving the opposing findings," Journal of Materials Chemistry B, vol. 3(29), pp.59575970, 2015.

[28] M.R Avadi, A. M. Sadeghi, M. Mohammadpour, "Preparation and characterization of insulin nanoparticles using chitosan and arabic gum with ionic gelation metod. J. Nanomeicine: vol. 6. 58-63, 2009.

[29] T. Phaechamud, "Hydrophobically modified chitosans and their pharmaceutical applications," J. of Pharmaceutical Science and Technology, vol. 1, pp.2-9, 2008.

[30] L. Qi and Z. Xu, "Lead sorption from aqueous solutions on chitosan nanoparticles," Colloids and Surfaces A: Physicochemical and Engineering Aspects, vol. 251(1-3), pp.183-190, 2004.

[31] S.D. Sarkar, B. L. Farrugia, T.R. Dargaville and S. Dhara, "Physicochemical/biological properties of tripolyphosphate cross-linked chitosan based nanofibers," Materials Science and Engineering: C, 33(3), pp.1446-1454, 2013. 